\title{
Glycyrrhetinic Acid Protects the Heart from Ischemia/Reperfusion Injury by Attenuating the Susceptibility and Incidence of Fatal Ventricular Arrhythmia During the Reperfusion Period in the Rat Hearts
}

\author{
Hong-Jin Wu Ji-Yuan Yang ${ }^{b}$ Min Jin ${ }^{b}$ Sheng-Qi Wang ${ }^{c}$ De-Lin Wu ${ }^{b}$ Yu-Na Liu \\ Xu Yan ${ }^{a, d}$ Cui Yang ${ }^{a}$ Ge Zhanga Jing He ${ }^{a}$ \\ aBeijing Haidian Hospital, Haidian Section of Peking University Third Hospital, Beijing, bBeijing Hospital \\ of Integrated Traditional Chinese and Western Medicine, Beijing, 'Beijing Institute of Radiation

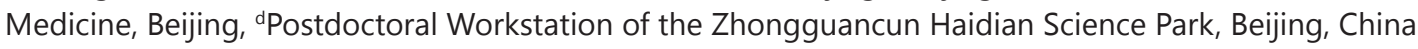

\section{Key Words}

Glycyrrhetinic acid • Ischemia/reperfusion • Arrhythmias • Ion channel

\begin{abstract}
Background/Aims: Licorice has been used to treat many diseases, including palpitations, in both Eastern and Western societies for thousands of years. It has been reported that glycyrrhetinic acid (GA), an aglycone saponin extracted from licorice root, exerts protective effects on the cardiovascular system, limits infarct sizes and protects against the development of arrhythmia. However, the mechanisms underlying the effects of glycyrrhetinic acid on the cardiovascular system remain poorly understood. This study aimed to determine the mechanisms underlying the protective effects of GA against lethal cardiac arrhythmias induced via ischemia-reperfusion in rat hearts, and to examine its electropharmacological properties. Materials and Methods: Anesthetized rats were divided into control (CTL), GA5, GA10, and GA20 groups. GA was administered intravenously $15 \mathrm{~min}$ before the occlusion of the left anterior descending coronary artery, at dosages of 5, 10 and $20 \mathrm{mg} / \mathrm{kg}$, respectively. Single ventricular myocytes were isolated using enzymolysis. The whole-cell patch clamp technique was utilized to record Ica, L, Ito and action potentials (APs). Results: During reperfusion, the incidence of ventricular fibrillation (VF) was decreased in each of the groups compared with the CTL group $(p<0.05)$. The ventricular tachycardia $(V T) / V F$ score was significantly decreased in
\end{abstract}

H.-J. Wu, J.-Y. Yang and M. Jin contributed equally to this paper.

Hong-Jin Wu

KARGER 125
Beijing Haidian Hospital, Haidian Section of Peking University Third Hospital,

29th Zhongguancun Setreet Beijing, 100080 (China)

E-Mail whjhdyyyz@yeah.net 
the GA20 group. Action potential durations (APDs) were prolonged by GA; both L-type calcium current (Ica-L) and transient outward potassium current (Ito) were blocked in a concentrationdependent manner by GA. Conclusion: These results suggest that GA attenuates both the susceptibility to and the incidence of fatal ventricular arrhythmia during reperfusion in rat hearts via the prolongation of the APD and the inhibition of both Ica- $L$ and Ito. GA appears to be a promising antiarrhythmic agent in the setting of ischemia/reperfusion.

Copyright $\odot 2015$ S. Karger AG, Basel

\section{Introduction}

Ischemic heart disease is one of the most significant problems facing clinicians in the industrialized world $[1,2]$. Reperfusion injury following a period of ischemia has recently drawn more attention, as thrombolytic therapy and primary percutaneous coronary intervention (PCI) are the most effective strategies with which to improve patients' clinical outcomes. Reperfusion arrhythmia (RA) is one of the consequences of myocardial reperfusion injury and is responsible for sudden cardiac death, most likely as a result of ion-channel dysfunction $[3,4]$. The electrophysiological characteristics of the ion channels located within the cardiomyocyte membrane are the primary targets of antiarrhythmic pharmacological research [5, 6]. However, the available antiarrhythmic drugs have clinical limitations because of their proarrhythmic effects. These effects are often related to highly selective single channel blocking actions. The inhibition of multiple channels has been suggested as both a safe and effective means of utilizing either amiodarone or potassium blockers, which prolong action potential durations (APDs) and the QT interval. [7, 8].

Licorice is derived from the root extract of a perennial herb and has been used to treat a variety of diseases, including heart palpitations, asthma, cough, angina, and stomach pain [9]. The early documented medicinal use of licorice may be traced back to ancient Assyrian, Egyptian, Chinese and Indian cultures [10]. GA, an aglycone saponin extracted from licorice root, is known for its antitumor, antiinflammatory and antihepatititic effects [11-14], and has been used worldwide. GA reportedly exerts protective effects on the cardiovascular system, including gap junction uncoupling [15], vasodilatory effects, negative inotropic effects [16, 17], and limiting infarct sizes during ischemia/reperfusion (I/R) [18]. The available evidence also suggests that GA exhibits antiarrhythmic activity in animal models of arrhythmias induced by chloroform adrenaline and $\mathrm{CaCl}_{2}[19]$. Our previous study demonstrated that GA reduced peak $\mathrm{I}_{\mathrm{Na}}$ and late $\mathrm{I}_{\mathrm{Na}}$ in Xenopus oocytes [20]. It has also been reported that GA exerts antiarrhythmic effects in the setting of myocardial ischemia via the blockage of Ina and Ica-L [21]. Additionally, GA inhibited potassium currents in both ventricular myocytes and HEK293 cells [22]. Although previous authors have reported that GA may be involved in the uncoupling of gap junctions, either prior to or during ischemia [23], the evidence pertaining to arrhythmias induced by I/R is scarce.

The present study was designed to investigate whether GA exerts antiarrhythmic effects in the setting of I/R in rats, as well as the possible electrophysiological mechanisms underlying these effects. Moreover, the electrophysiological effects of GA on cardiac APDs and membrane currents were recorded in individual myocytes from rat hearts.

\section{Materials and Methods}

Ethics statement: All experiments were approved by the Institutional Animal Care and Use Committee of Beijing Haidian Hospital (Haidian Section of Peking University Third Hospital).

Materials

GA was provided by the Chinese Biological Product Assay Institute (Beijing, China). Taurine, L-glutamic acid, ethylene glycol bis (2-N b ether) tetraacetic acid (EGTA), 4-(2-hydroxyerhyl) piperazine-erhanesulfonic 
acid (HEPES), $\mathrm{NaCl}, \mathrm{KCl}, \mathrm{CaCl}_{2}, \mathrm{MgCl}_{2}, \mathrm{CsCl}, \mathrm{NaH}_{2} \mathrm{PO}_{4}, \mathrm{Na}_{2} \mathrm{ATP}, \mathrm{KH}_{2} \mathrm{PO}_{4}, \mathrm{DMSO}, \mathrm{CsOH}, \mathrm{KOH}, \mathrm{KOH}$, and $\mathrm{NaOH}$ were each purchased from Sigma-Aldrich. Collagenase II was purchased from the Worthington Biochemical Corporation. Male adult Sprague-Dawley (SD) rats (220 - $250 \mathrm{~g}$ ) obtained from Vital River Laboratories were used for each of the experiments.

\section{Sample preparations}

A Tyrode solution was prepared by mixing $137 \mathrm{mM} \mathrm{NaCl}, 5.4 \mathrm{mM} \mathrm{KCl}, 1.8 \mathrm{mM} \mathrm{CaCl}_{2}, 0.33 \mathrm{mM} \mathrm{NaH}_{2} \mathrm{PO}_{4^{\prime}}$ $1.0 \mathrm{mM} \mathrm{MgCl}, 10 \mathrm{mM}$ HEPES and $10 \mathrm{mM}$ Glucose. The $\mathrm{pH}$ was adjusted to 7.4 with $\mathrm{NaOH}$. The isolated cardiomyocytes were stored in Krebs buffer (KB) solution containing the following (in $\mathrm{mM}$ ): $40 \mathrm{KCl}, 20$ $\mathrm{KH}_{2} \mathrm{PO}_{4}, 20$ taurine, $3.0 \mathrm{MgCl}_{2}, 70 \mathrm{KOH}, 50 \mathrm{~L}$-glutamic acid, $0.5 \mathrm{EGTA}, 10 \mathrm{HEPES}$, and 10 glucose; the pH was adjusted to 7.4 with $\mathrm{KOH}$. To record whole-cell $\mathrm{I}_{\text {ca, }}$ a pipette solution containing the following was used (in $\mathrm{mM}$ ): $120 \mathrm{CsCl}, 1 \mathrm{CaCl}_{2}, 5 \mathrm{MgCl}_{2}, 10 \mathrm{HEPES}, 11 \mathrm{EGTA}, 5 \mathrm{Na}_{2} \mathrm{ATP}$, and 11 glucose; the $\mathrm{pH}$ was adjusted to 7.2 with $\mathrm{CsOH}$. In order to isolate $\mathrm{I}_{\text {ca, } \mathrm{L}^{\prime}}$ a bath solution containing the following was used (in $\mathrm{mM}$ ): 137 $\mathrm{NaCl}, 5.4 \mathrm{KCl}, 1.8 \mathrm{CaCl}_{2}, 0.33 \mathrm{NaH}_{2} \mathrm{PO}_{4}, 1.0 \mathrm{MgCl}_{2}, 10$ HEPES, and 10 glucose; the $\mathrm{pH}$ was adjusted to 7.4 with $\mathrm{NaOH}$. In order to record whole-cell $\mathrm{I}_{\text {to }}$, a pipette solution containing the following was used (in $\mathrm{mM}$ ): $140 \mathrm{KCl}, 1 \mathrm{MgCl}_{2}, 5 \mathrm{~K}_{2} \mathrm{ATP}, 5 \mathrm{EGTA}$, and 10 HEPES; the $\mathrm{pH}$ was adjusted to 7.2 with $\mathrm{KOH}$. To isolate $\mathrm{I}_{\text {to }}$ a bath solution containing the following was used (in $\mathrm{mM}$ ): $140 \mathrm{NaCl}, 4 \mathrm{KCl}, 1.5 \mathrm{CaCl}_{2}, 1 \mathrm{MgCl}_{2}, 0.5 \mathrm{CdCl}_{2}, 5 \mathrm{HEPES}$, and 10 glucose; the $\mathrm{pH}$ was adjusted to 7.4 with $\mathrm{NaOH}$. In order to record whole-cell $\mathrm{AP}$, a pipette solution containing the following was used (in mM): $120 \mathrm{KCl}, 1 \mathrm{CaCl}_{2}, 1 \mathrm{MgCl}_{2}, \mathrm{Na}_{2} \mathrm{ATP}\left(3 \mathrm{H}_{2} \mathrm{O}\right), 11$ EGTA, HEPES, and 11 glucose; the $\mathrm{pH}$ was adjusted to 7.2 with $\mathrm{KOH}$. In order to record APs, a bath solution containing the following was used (in $\mathrm{mM}$ ): $137 \mathrm{NaCl}, 5.4 \mathrm{KCl}, 1.8 \mathrm{CaCl}_{2}, 0.33 \mathrm{NaH}_{2} \mathrm{PO}_{4}, 1.0 \mathrm{MgCl}_{2}, 10 \mathrm{HEPES}$, and 10 glucose; the $\mathrm{pH}$ was adjusted to 7.4 with $\mathrm{NaOH}$. For the whole cell patch clamp experiments, GA powder was dissolved in dimethylsulfoxide (DMSO) as stock. The percentage of DMSO in the final solution was less than $0.1 \%$.

\section{Myocardial Ischemia Reperfusion Model}

All surgical procedures were performed as described previously [24]. Briefly, the SD rats were weighed and anesthetized via an intraperitoneal injection of pentobarbital $(50 \mathrm{mg} / \mathrm{kg}$ ). The rats were intubated and ventilated with $100 \%$ oxygen $(220 \mu \mathrm{l}$ stroke volume, 60 strokes $/ \mathrm{min})$ using a respirator (BL420E, Taimeng, China). A thoracotomy was performed, and the left anterior descending coronary artery (LAD) was visualized and ligated proximally using a 6-0 silk suture. A piece of PE-10 tubing was placed between the left coronary artery and the 6-0 silk suture to minimize the coronary artery trauma induced via occlusion and facilitate reperfusion. The LAD was completely occluded for $10 \mathrm{~min}$; the reperfusion (30 min) was subsequently initiated via the removal of the 6-0 suture. This study conformed to the Guide for the Care and Use of Laboratory Animals published by the U.S National Institutes of Health.

\section{The evaluation of the arrhythmias}

The arrhythmias were defined and analyzed based on the criteria of the Lambeth Conventions [25]. The ECG recordings were analyzed for ventricular arrhythmias during both ischemia and reperfusion. The arrhythmia scores were measured as previously described [26]. The arrhythmias were categorized into 5 groups and assigned the following point values: no arrhythmias, 0 points; premature atrial or ventricular beats, 1 point; supraventricular tachycardia or paired premature ventricular beats, 2 points; bigeminal or trigeminal premature ventricular beats or nonsustained ventricular tachycardia ( $\geq 3$ consecutive premature ventricular beats), 3 points; and sustained ventricular tachycardia ( $>10$ consecutive premature ventricular beats) or polymorphic ventricular tachycardia, 4 points.

\section{Measurements of $\mathrm{Ca}^{2+}$ content in the myocardial cells}

After 30 mins, the rats with myocardial ischemia and reperfusion were killed; their chests were immediately opened, and the hearts were removed; the anterior wall myocardial infarct areas were flushed with iced saline, and excess moisture was absorbed with filter paper; the specimens were refrigerated at $-70^{\circ} \mathrm{C}$ before being weighed and placed in tissue homogenizer, to which ice-saline was added at a 1:9 weight ratio. The homogenizer was placed into an ice water mixture, after which the tissues were ground and centrifuged at $2500 \mathrm{rpm} / \mathrm{min}$. Following $20 \mathrm{~min}$ of centrifugation, the supernatant was removed, and an electrolyte analyzer was used to measure the concentration of $\mathrm{Ca}^{2+}$. 


\section{The isolation of the cardiac ventricular myocytes}

The cardiac ventricular myocytes were enzymatically isolated from the SD rats. Briefly, the rats were anesthetized via the administration of chloral hydrate at a dose of $3.5 \mathrm{ml} \mathrm{kg}^{-1}$ and heparinized with 1000 $\mathrm{U}$ heparin. Under anesthesia, the hearts were rapidly removed and mounted on a Langendorff apparatus before being retrogradely perfused through the aorta using $\mathrm{Ca}^{2+}$-free Tyrode solution at a constant rate of $5 \mathrm{ml} / \mathrm{min}$. After allowing the blood to drain from the heart (over approximately $5 \mathrm{~min}$ ), the perfusate was replaced with a low calcium enzyme solution containing $0.05 \mathrm{mmol} / \mathrm{L} \mathrm{CaCl}_{2}, 0.4 \mathrm{mg} / \mathrm{ml}$ collagenase (Type II; Worthington, USA), $0.04 \mathrm{mg} / \mathrm{ml}$ protease (Type XVI) and $0.25 \mathrm{mg} / \mathrm{ml}$ bovine serum albumin, $\mathrm{pH}$ 7.4. Following 25-30 min of perfusion with an enzyme solution, the ventricles were cut from the heart and minced. The resulting myocyte suspension was subsequently filtered and stored in fresh KB solution at room temperature. The myocytes were used for the experiments within $10 \mathrm{~h}$ following the isolation procedure. All solutions were gassed with $100 \% \mathrm{O}_{2}$ at $37^{\circ} \mathrm{C}$.

\section{Electrophysiological recording}

Individual rod-shaped cells with well visible striations were used for the membrane voltage and current recordings, using the whole-cell patch clamp technique. The patch pipettes were pulled from borosilicate glass capillary tubes using a horizontal micropipette puller (P-97; Sutter Instruments, USA). The resistances of the filled glass electrodes ranged from 1.5 - $2 \mathrm{M} \Omega$. The currents were monitored using a patch clamp amplifier (Axopatch 200B; Molecular Devices, USA) interfaced with a digitizer (Digidata 1440A; Molecular Devices, USA) and a computer. The data acquisition and analyses were conducted using pClamp 10.1 (Molecular Devices), and additional analyses were performed using Origin 7.0 (Origin-lab, Northampton, MA). All experiments were performed at room temperature. The $\mathrm{n}$ denotes the number of myocytes from which the current recordings were obtained.

\section{Experimental protocols}

The rats were randomly placed in five experimental groups. The control animals were infused with saline through the femoral vein for $3 \mathrm{~min}$ before being subjected to a $10 \mathrm{~min}$ occlusion period and a $30 \mathrm{~min}$ reperfusion period involving the LAD. Glycyrrhetinic acid dissolved in saline to final concentrations of 5, 10, $20 \mathrm{mg} / \mathrm{kg}$ was administered to an additional 10 rats under similar conditions.

\section{Statistical analysis}

All data were analyzed using SPSS 11.5 software. The group data were expressed as means \pm SEs. Paired sample t-tests were used to compare the electrophysiological data among the groups. A two-tailed P $<0.05$ was indicative of a statistically significant difference. Compared with the control rats, GA significantly diminished the incidence of both ventricular tachycardia and ventricular fibrillation. The GA group (5, 10 and $20 \mathrm{mg} / \mathrm{kg}$ ) also exhibited reduced total VT and VF durations following reperfusion. The doses administered to the rats from the GA group, $(5,10$ and $20 \mathrm{mg} / \mathrm{kg}$ ) resulted in significantly lower frequencies of I/R-induced VT, frequencies of $16 \pm 6,13 \pm 6$, and $10 \pm 5$, respectively $(n=8, P<0.05)$, and VF $(5 \pm 3,4 \pm 3,3 \pm 1$, $\mathrm{n}=8, \mathrm{P}<0.05$ ) (Fig. 1D).

\section{Results}

The effects of GA on the ventricular arrhythmias induced by $I / R$ in the rats

Figure 1 depicts the protective effects exerted by GA against I/R-induced ventricular tachycardia (VT) and ventricular fibrillation (VF). The rats received intravenous GA (GA group: 5, 10 and $20 \mathrm{mg} / \mathrm{kg}$ ) and were subjected to $10 \mathrm{~min}$ of ischemia via coronary artery ligation, followed by $30 \mathrm{~min}$ of reperfusion.

The representative ECGs depicting sinus rhythm, VT and VF are included in Figure $1 \mathrm{~A}$. The corresponding details are included in Figures 1B, 1C and 1D.

Compared with the control rats, GA significantly diminished the incidence of both ventricular tachycardia and ventricular fibrillation. The concentrations of $5-20 \mathrm{~kg} / \mathrm{mg}$ significantly reduced the incidences of VT (12.5-35.5\%) and VF (12.5-50\%) (Fig. 1B).

The GA group (5, 10 and $20 \mathrm{mg} / \mathrm{kg}$ ) also exhibited reduced total VT and VF durations following reperfusion, as follows: $168 \pm 47$ to $161 \pm 53,135 \pm 46$ and $113 \pm 48 \mathrm{~s}(\mathrm{n}=8, \mathrm{p}<0.05)$, 
Wu et al.: Glycyrrhetinic acid Inhibits Both L-Type Calcium Current (Ica-L) and Transient Outward Potassium Current (Ito) During the Reperfusion Period in Rat Hearts

Fig. 1. The effects of GA on reperfusion-induced ventricular arrhythmias in anesthetized rats. (A) Representative ECG tracings obtained in rats with sinus rhythm, VT and VF. (B) The administration of GA reduced the incidence of reperfusion-induced VT/VF. (C) The duration of VT/VF was also reduced via treatment with GA. (D) At the end of reperfusion, the frequency of VT and VF was lower in the GA-treated rats. (E) GA treatment also decreased arrhythmia scores compared with the I/R group.

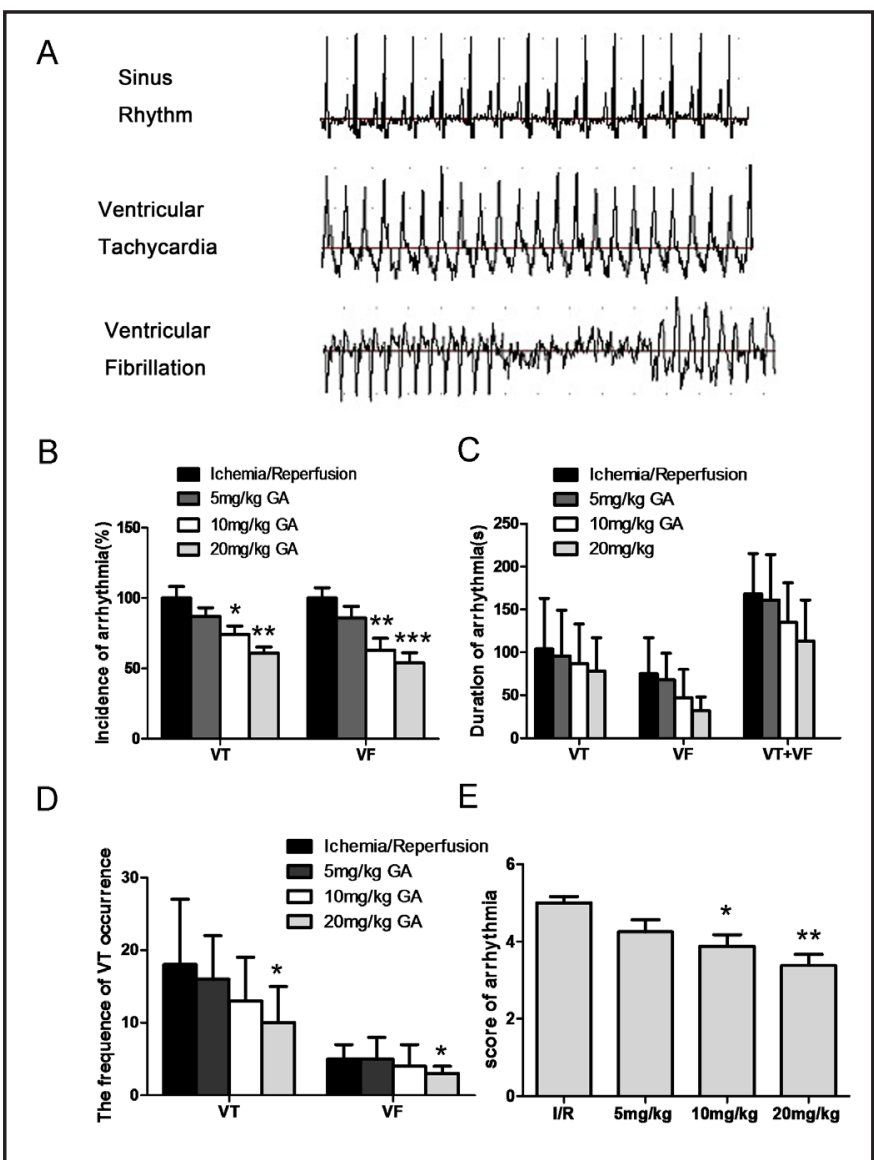

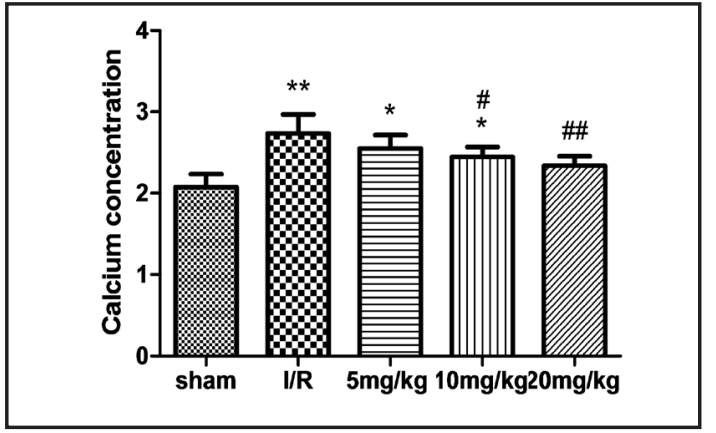

Fig. 2. The effects of GA on $\left[\mathrm{Ca}^{2+}\right]_{\mathrm{i}}$ overload in cardiomyocytes. The GA group significantly inhibited $\mathrm{Ca}^{2+}$ content in a dose-dependent manner compared with the control group.

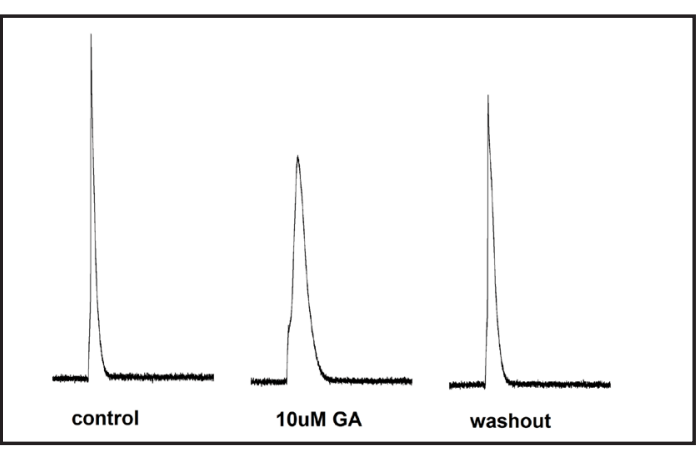

Fig. 3. Representative action potential tracings recorded from individual cardiomyocytes. GA prolongs cardiac action potentials in rat ventricular myocytes.

and decreased the VT durations from $104 \pm 59$ to $96 \pm 53,87 \pm 46$ and $78 \pm 39 \mathrm{~s}(\mathrm{n}=8, \mathrm{p}<0.05)$, and reduced the VF durations from $75 \pm 42$ to $68 \pm 31,47 \pm 33$ and $32 \pm 16 \mathrm{~s}(\mathrm{n}=8, \mathrm{p}<0.05)$ (Fig. 1C).

During the 30 min reperfusion period, the hearts in the control group developed VT and $\mathrm{VF}$ at frequencies of $18 \pm 9$ and $5 \pm 2$, respectively. Compared with the control group, GA at the doses of 5, 10 and $20 \mathrm{mg} / \mathrm{kg}$ significantly decreased the frequencies of I/R-induced VT to $16 \pm 6,13 \pm 6$ and $10 \pm 5$, respectively $(n=8, P<0.05)$, as well as the frequencies of $V F(5 \pm 3$, $4 \pm 3,3 \pm 1, \mathrm{n}=8, \mathrm{P}<0.05$ ) (Fig. 1D). 
Table 1. The effects of GA $(10 \mathrm{uM})$ on APD in rat ventricular myocytes. The data are expressed as means \pm S.E.M., ${ }^{*} \mathrm{P}<0.05$, control vs. GA $10 \mu \mathrm{M}$; RMP, resting membrane potential; APA, action potential amplitude; APD50 and APD90, action potential duration at $50 \%$ and $90 \%$ repolarization, respectively

\begin{tabular}{lllll}
\hline Group & RMP $(\mathrm{mV})$ & APA $(\mathrm{mV})$ & APD50 $(\mathrm{ms})$ & APD90 (ms) \\
\hline control & $-70.4 \pm 2.5$ & $91.7 \pm 5.1$ & $45.9 \pm 1.6$ & $79.2 \pm 3.4$ \\
GA & $-68.4 \pm 2.6$ & $49.2 \pm 6.4^{*}$ & $106.9 \pm 2.7^{*}$ & $161.2 \pm 3.7^{*}$ \\
washout & $-69.7 \pm 3.1$ & $80.1 \pm 6.3$ & $49.8 \pm 1.9$ & $86.7 \pm 2.6$ \\
\hline
\end{tabular}

Fig. 4. GA inhibited $\mathrm{I}_{\text {ca-L }}$ in the rat ventricular myocytes. I $_{\text {ca-L }}$ was activated by $400 \mathrm{~ms}$ depolarizing steps from -40 to + $60 \mathrm{mv}$, with a holding potential of -40 mv and an interpulse interval of $10 \mathrm{~s}$. (A) Representative raw current tracings under controlled conditions. (B) An example of the inhibitory effects of GA on I $\mathrm{I}_{\text {ca-L }}$. (C) I-V relationships under both controlled conditions and in the presence of GA ( $\mathrm{n}$ = 7). (D) Examples of experimental recordings depicting changes in $\mathrm{I}_{\text {ca-L }}$ at different concentrations of GA as a function of time. $\mathrm{I}_{\text {ca-L }}$ was elicited via a depolarizing pulse at a holding potential of -40 to $0 \mathrm{mv}$.
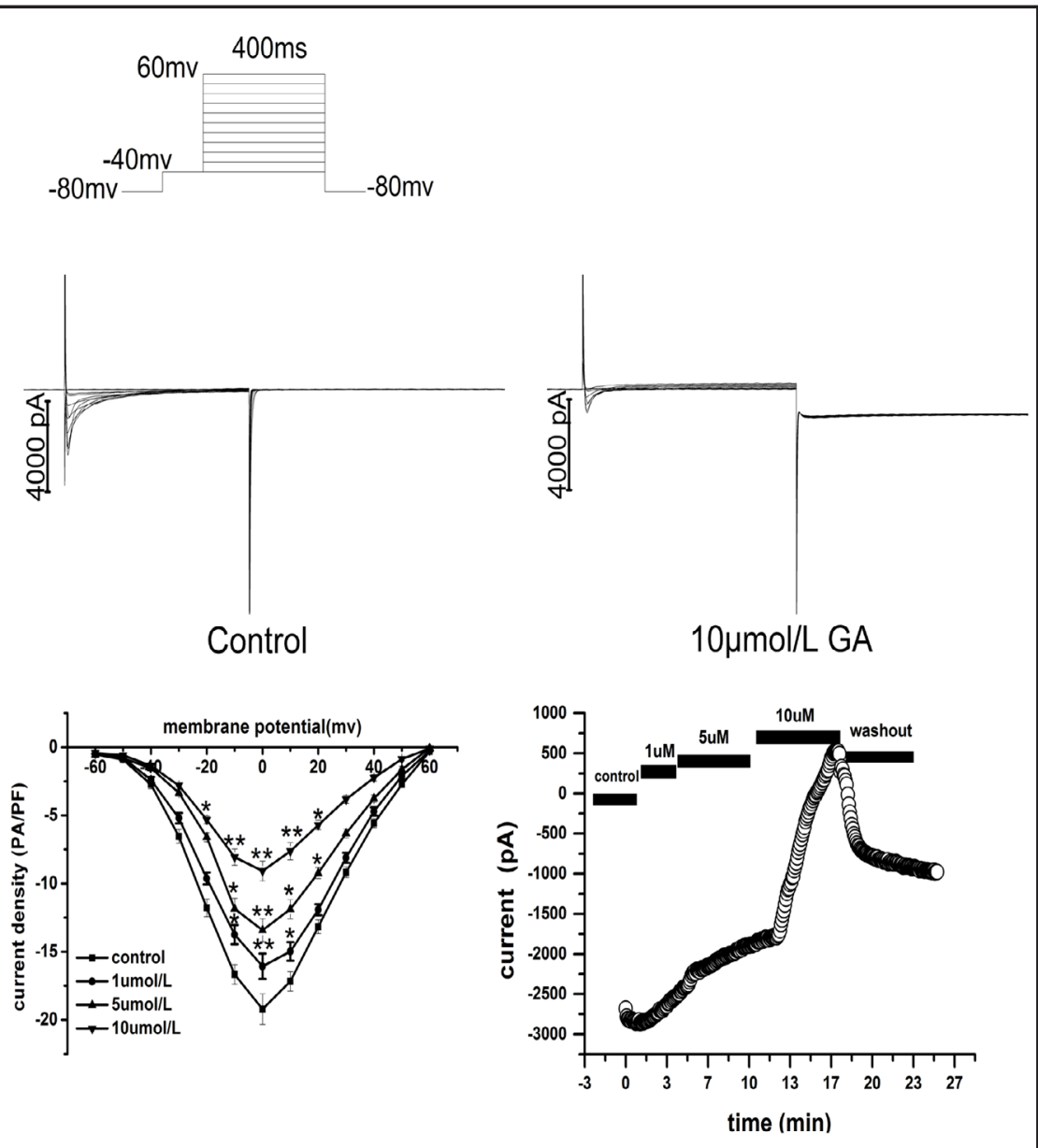

We also quantified arrhythmias via modified arrhythmia scores; the GA group exhibited a lower arrhythmia score than the control group $(4.25 \pm 0.89,3.88 \pm 0.84,3.38 \pm 0.92$ vs. $5 \pm$ $0.46, \mathrm{n}=8, \mathrm{P}<0.05$ ) (Fig. 1E).

The effects of GA on the $\left[\mathrm{Ca}^{2+}\right]_{i}$ levels in the cardiomyocytes

Substantial calcium overload induces reperfusion injury; the inhibition of calcium overload may interrupt the cascade of events leading to reperfusion-induced arrhythmias. We investigated the effects of GA on reperfusion-induced $\left[\mathrm{Ca}^{2+}\right]_{\mathrm{i}}$ overload in rat hearts. Figure 2 depicts the calcium concentrations of the hearts before and after the addition of GA. In 
Wu et al.: Glycyrrhetinic acid Inhibits Both L-Type Calcium Current (Ica-L) and Transient Outward Potassium Current (Ito) During the Reperfusion Period in Rat Hearts

Fig. 5. GA inhibited $I_{\text {to }}$ in rat ventricular myocytes. $\mathrm{I}_{\text {to }}$ was activated by $400 \mathrm{~ms}$ depolarizing steps from -40 to $+60 \mathrm{mv}$, with a holding potential of $-40 \mathrm{mv}$ at an interpulse interval of $10 \mathrm{~s}$. (A) Representative raw current tracings under controlled conditions. An example of the inhibitory effect of GA on $\mathrm{I}_{\text {to }}$ and I-V relationships under controlled conditions in the presence of GA $(n=7)$. (B) Examples of experimental recordings depicting changes in $\mathrm{I}_{\text {ca-L }}$ at different concentrations of GA as a function of time. $I_{\text {to }}$ was elicited via a depolarizing pulse at a holding potential of -40 to $+60 \mathrm{mv}$.

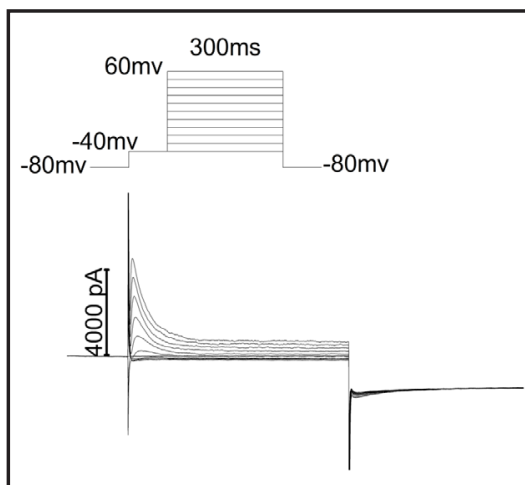

Control

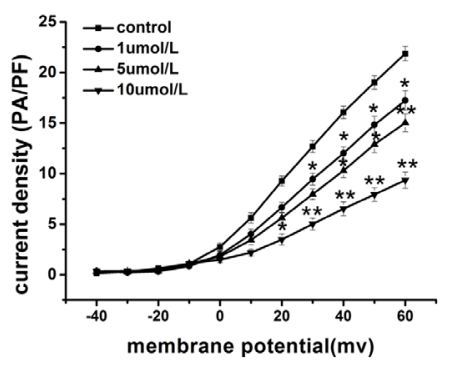

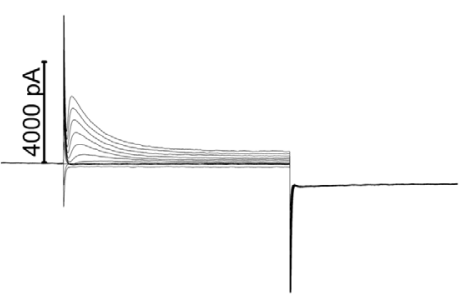

$10 \mu \mathrm{mol} / \mathrm{L} \mathrm{GA}$

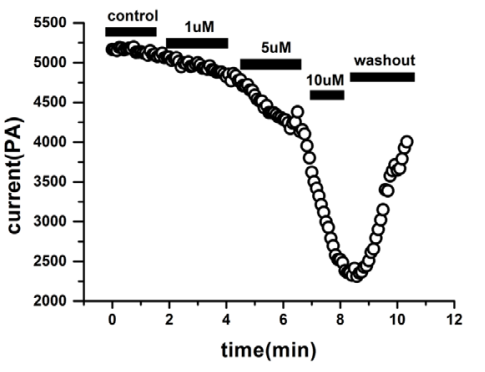

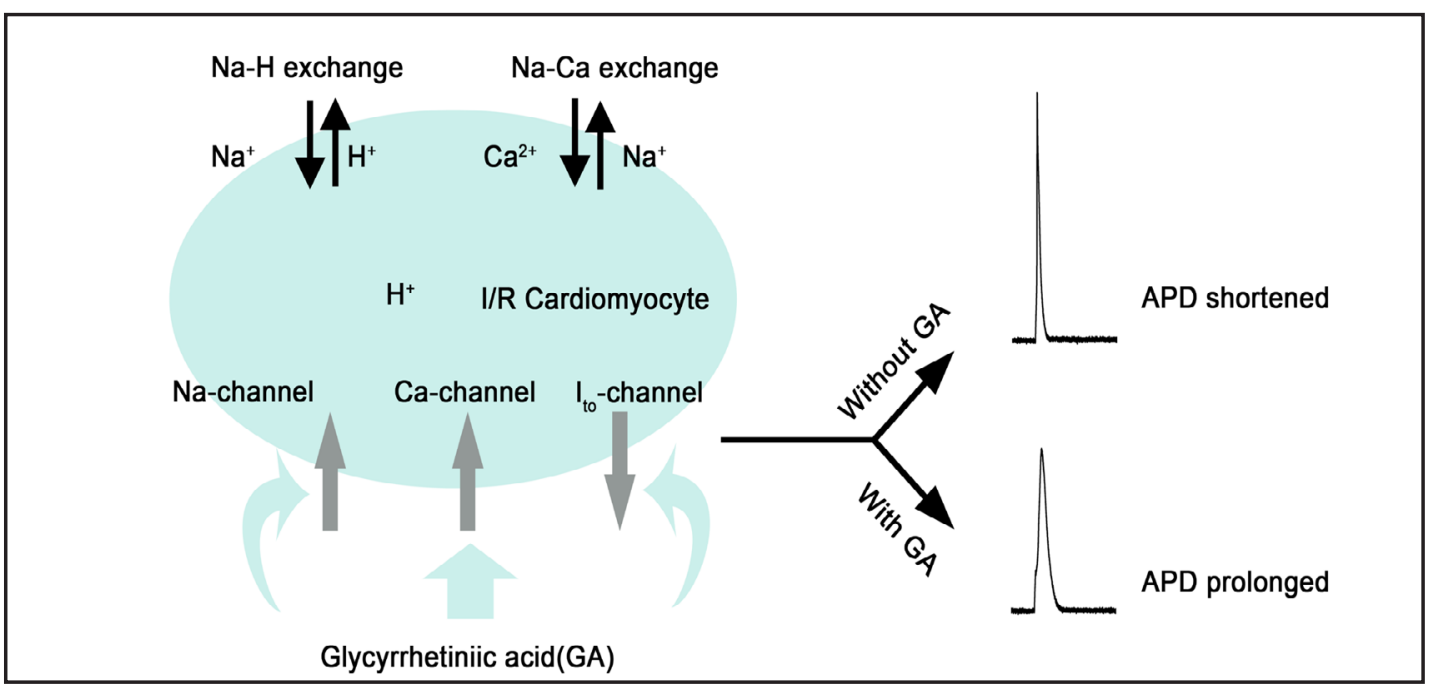

Fig. 6. A schematic model demonstrating the protective effects of GA via the prolongation of the APD as a result of the inhibition of both Ica-L and Ito.

this figure, compared with the sham group, the $\mathrm{Ca}^{2+}$ content of I/R group was significantly improved $(\mathrm{P}<0.05)$, indicating that the heart muscle exhibits severe injury following I/R. Compared with the control group, the $\mathrm{Ca}^{2+}$ content in each of the GA groups was inhibited in a dose-dependent manner $(\mathrm{P}<0.05)$, a finding indicative of the protective effects of GA.

The effects of GA on action potential duration in the rat ventricular myocytes

Figure 3 depicts the action potentials recorded in the ventricular myocytes isolated from the rat hearts using the current-clamp technique. A 5 ms depolarizing stimulatory pulse was administered in order to trigger the action potential. Resting potential (RP), $50 \%\left(\mathrm{APD}_{50}\right)$ and $90 \%\left(\mathrm{APD}_{90}\right)$ repolarization were used to describe the action potential changes. GA $(10$

\section{KARGER}


$\mu \mathrm{M})$ was perfused to the cells after the normal action potential was recorded. The results indicated that GA $(10 \mu \mathrm{M})$ resulted in prolonged APDs in the myocytes.

Table 1 demonstrated the effect of GA $(10 \mu \mathrm{M})$ on APD in the rat ventricular myocytes. In this Table, the $\mathrm{APD}_{50}$ was prolonged from $45.9 \pm 1.6$ to $106.9 \pm 2.7 \mathrm{~ms}(\mathrm{n}=7, \mathrm{p}<0.05)$, and the $\mathrm{APD}_{90}$ was also prolonged from $79.2 \pm 3.4$ to $161.2 \pm 3.7 \mathrm{~ms}$.

The effects of GA on Ica- $L$ in the rat ventricular myocytes

The cardiomyocytes were placed in an experimental chamber and continuously perfused using extracellular solution. $\mathrm{I}_{\mathrm{Na}}$ was inactivated at a holding potential of $-50 \mathrm{mv}$. Figure 2A depicts the superimposed Ica-L tracings recorded by applying $400 \mathrm{~ms}$ pulses from -50 to $+60 \mathrm{mv}$ before the addition of GA and following the administration of GA. GA reduced the Ica-L at every potential, as illustrated by the current-voltage (I-V) curves included in Figure 4A. The peak was slightly shifted to a more positive value.

\section{The effects of GA on Ito in the rat ventricular myocytes}

The $I_{\text {to }}$ currents were elicited via square test pulses of 300 ms ranging from -40 to +50 $\mathrm{mv}$, from a holding potential of $-80 \mathrm{mv}$. The outward peak amplitude was measured as $\mathrm{I}_{\text {to }} \mathrm{I}_{\text {to }}$ was the predominant repolarizing potassium current in the rat ventricular myocytes. At a testing potential of $+50 \mathrm{mv}, 10 \mu \mathrm{M}$ GA reduced $\mathrm{I}_{\text {to }}$ from $4.1 \pm 0.9 \mathrm{nA}$ to $2.3 \pm 0.6 \mathrm{nA}(\mathrm{n}=8, \mathrm{P}<$ $0.05)$. Figure 3 depicts the effects of GA on $I_{\text {to }}$.

\section{Discussion}

Acute myocardial infarction is caused by the death of myocardial cells as a result of the thrombotic occlusion of coronary arteries. Acute myocardial infarction is the leading cause of death in the setting of human cardiovascular disease [27, 28]. Swift restoration of the normal blood supply is the only effective means of minimizing cardiac injury. However, reperfusion itself may also cause myocardial injury and cardiac dysfunction, a phenomenon known as "reperfusion injury." Therefore, mitigating myocardial ischemia-reperfusion (I/R) injury is an important means of treating ischemic heart disease [29-31].

Although reperfusion is essential for preventing irreversible cellular injury and preserving ventricular function, reperfusion and recovery from ischemia-induced metabolic, ionic, electrical, and signaling transduction changes cause ventricular arrhythmia, cellular injury and sudden death [33-37].

The mechanisms underlying ventricular arrhythmia in acute myocardial ischemia and reperfusion have been studied primarily in animal models. Consistent with the findings of previous studies, the present study determined that left main coronary artery occlusion and release resulted in ventricular arrhythmias, including premature ventricular beats, ventricular tachycardia and ventricular fibrillation in rats. The effects of GA on the ischemiareperfusion arrhythmias were studied in a rat model of myocardial ischemia-reperfusion injury. The administration of GA prior to the onset of ischemia resulted in a dose-dependent reduction in the incidence of ischemia-reperfusion induced arrhythmia, including both ventricular tachycardia and ventricular fibrillation.

The reperfusion of the ischemic myocardium is associated with several pathologic derangements, including reperfusion arrhythmias [35]. Malignant ventricular arrhythmias resulting in cardiovascular collapse are believed to the primary mechanism underlying sudden death. The mechanism of arrhythmogenesis caused by I/R injury has not yet been elucidated. Ischemia/reperfusion (IR) injury refers to the tissue damage caused when blood returns to the affected tissue following a period of ischemia. The absence of both oxygen and nutrients from the blood during ischemia creates a condition in which the restoration of circulation results in both inflammation and oxidative damage via the induction of oxidative stress as opposed to the restoration of normal function [38, 39], which means that the progressive and irreversible damage incurred during ischemia may only be 
stopped via immediate reperfusion. Otherwise, severe and irreversible myocardial damage may result from reperfusion itself, a phenomenon referred to as reperfusion injury. An important consequence of myocardial I/ $R$ is the disturbance of cardiac rhythm, including the development of $\mathrm{VF}$, a potentially lethal arrhythmia. $\left[\mathrm{Ca}^{2+}\right]_{\mathrm{i}}$ homeostasis plays a central role in the cardiovascular system, particularly where arrhythmias are concerned[40]. The pathophysiological mechanisms underlying the development of VT and VF include the overproduction of oxygen-derived free radicals and calcium overload during the initial stages of reperfusion.

During myocardial reperfusion, there is an abrupt increase in intracellular $\mathrm{Ca}^{2+}$, which overwhelms the normal mechanisms of $\mathrm{Ca}^{2+}$ regulation in cardiomyocytes and results in both intracellular and mitochondrial $\mathrm{Ca}^{2+}$ overload, which causes cardiomyocyte death via the hypercontracture of the affected cardiac cells. Attenuating intracellular $\mathrm{Ca}^{2+}$ overload with pharmacologic antagonists of sarcolemmal $\mathrm{Ca}^{2+}$ ion channels decreases myocardial infarct sizes in experimental studies. During ischemia/reperfusion, the cardiac myocytes encounter adenosine triphosphatase (ATP) depletion; therefore, the $\mathrm{Na}^{+}-\mathrm{K}^{+}$-ATPase is inhibited, which results in increased intracellular $\mathrm{Na}^{+}$concentrations and the activation of the $\mathrm{Na}^{+}-\mathrm{Ca}^{2+}$ exchanger, which promotes $\mathrm{Ca}^{2+}$ entry and the subsequent development of intracellular $\mathrm{Ca}^{2+}$ overload [41-43]. Additionally, reperfusion injury may cause the release of metabolites, which may affect resting membrane potential, intracellular $\mathrm{Ca}^{2+}$ concentrations and ion channel function $[44,45]$. In the present study, we observed that GA decreases the incidence of I/R injury-induced arrhythmia.

In cardiac myocytes, there exist various ion channels, including sodium channels, calcium channels, and potassium channels. Cardiac electrical activity is well organized as a result of the functional and structural equilibrium of these various channels[46]. Any abnormality in ion channel function may result in changes in the action potential durations of the ventricular myocytes, which may cause arrhythmia.

Previous studies have demonstrated that electrophysiological changes in AP profiles, changes such as APD prolongation and modifications in both potassium and calcium current, are accompanied by the prolongation of either the QT interval or the APD by medicinal compounds, which has become a major concern among medical professionals and within the pharmaceutical industry, as the medications in question may exert proarrhythmic effects. The use of specific Ikr blockers such as E-4031 in the treatment of various ventricular arrhythmias is accompanied by an increased likelihood of proarrhythmic episodes, particularly TdP. Combination therapy with quinidine (Ina-f, Ikr and Ina-l blocker) and mexiletine (Ina blocker) is more effective at preventing ventricular tachycardia and ventricular fibrillation in both animal models and humans compared with mono-drug therapy. Therefore, the inhibition of multiple channels has been suggested as a means of improving both the safety and the efficacy of potassium blockers, which prolong APDs and the QT interval, without inducing EADs or triggering TdP. The efficacy of amiodarone and its low incidence of proarrhythmic effects may be attributed to this complex multi-channel inhibition. Our data suggest that GA fits this electrophysiological profile and induces the progressive prolongation of APDs in isolated ventricular myocytes in a concentrationdependent manner. The observed alterations were accompanied by specific changes in membrane current as determined via voltage-clamp measurements. Perfusion with GA resulted in decreased $\mathrm{I}_{\text {to }}$ and $\mathrm{I}_{\mathrm{Ca}}{ }^{2+}$. Taken together, these results demonstrate that GA exerts antiarrhythmic effects in the setting of rat $\mathrm{I} / \mathrm{R}$ and induces electrophysiological alterations in ventricular myocytes.

GA may exert antiarrhythmic effects via the prolongation of APDs and effective refractory periods (ERPs) by blocking potassium channels. The prolongation of APDs via GA administration results primarily from the blockade of $\mathrm{I}_{\text {to }}$. The blockade of $\mathrm{I}_{\text {na- }}$ Land $\mathrm{I}_{\text {ca- }} \mathrm{L}$ by GA attenuated APD prolongation. The inhibition of Ito was greater than the inhibition of both Ica-L and Ina. As a result, the net outward current decreased, prolonging the APD. GA is similar to ranolazine and amiodarone in terms of the inhibitory effects it exerts on multiple cardiac ion channels, including Ina-L, Ito and Ica-L. Our previous study suggested 
that glycyrrhetinic acid blocks cardiac sodium currents, particularly late $\mathrm{I}_{\mathrm{Na}}$. Penkoske's results suggested that the cardiac electrophysiology underlying reperfusion arrhythmias was characterized by refractory period shortening. A pure Ica-L blocker may aggravate this tendency; however, it may also counter-balance the contradiction via the simultaneous inhibition of $\mathrm{I}_{\text {to }}$. Under these conditions, the blockade of multi-channels may be more useful than the inhibition of a single type of ion channel.

Our results indicate that GA acts on both calcium and potassium channels and exerts effects similar to those of class III drugs such as amiodarone. These effects give rise to voltage-dependent effects. Intravenous amiodarone is the drug of choice for the treatment of ventricular tachycardia/fibrillation (VT/VF) in emergency medicine. However, the onset of amiodarone's effects occurs at 6-8 $\mathrm{h}$ following its administration. Furthermore, its intravenous use is occasionally accompanied by hypotension and bradycardia, effects that make its use as a rescue medication in life-threatening situations difficult.

Recently, researchers have focused on newer class III antiarrhythmic agents such as nifekalant hydrochloride, which acts by increasing the time course of myocardial repolarization. Nifekalant is available only as an intravenous agent and is used in the treatment of ventricular tachyarrhythmia; it was approved in Japan in June of 1999, the only country in which it is currently used. Life-threatening ventricular tachyarrhythmias such as VT or VF are likely to develop during the acute phase of ACS (acute coronary syndrome); these arrhythmias exert important effects on the prognoses of affected patients.

Recent studies have demonstrated that agents with multiple channel (including $\mathrm{I}_{\mathrm{Na}-\mathrm{L}}$ ) blocking actions may be a viable approach to treating various arrhythmias induced via I/R and may be less proarrhythmic than selective ion channel inhibitors [47]. Therefore, GA may represent a novel therapeutic intervention in the treatment of I/R injury-induced arrhythmia.

In conclusion, the results of this study suggest that treatment with GA, particularly at a dosage of $20 \mathrm{mg} / \mathrm{kg}$, attenuates both the susceptibility to and the incidence of fatal ventricular arrhythmia during reperfusion in rats. This protective effect is apparently mediated via the prolongation of APDs as a result of the inhibition of Ica-L and Ito. Therefore, GA may be a promising antiarrhythmic agent in the setting of ischemia/reperfusion.

\section{Acknowledgements}

This project was supported by the Beijing Key Disciplines Project of Traditional Chinese Medicine (no. JZZ-312) and the Chinese National Natural Science Foundation (no. 30672586).

\section{Disclosure Statement}

No conflicts of interest, financial or otherwise, are declared by the authors.

\section{References}

1 Feng M, Xiang JZ, Ming Z, Fu Q, Ma R, Zhang QF, Dun YY, Yang L, Liu H: Activation of epidermal growth factor receptor mediates reperfusion arrhythmias in anaesthetized rats. Cardiovasc Res 2012;93:60-68.

2 Vincent A, Gahide G, Sportouch-Dukhan C, Covinhes A, Franck-Miclo A, Roubille F, Barrère C, Adda J, Dantec C, Redt-Clouet C, Piot C, Nargeot J, Barrère-Lemaire S: Down-regulation of the transcription factor ZAC1 upon pre- and postconditioning protects against I/R injury in the mouse myocardium. Cardiovasc Res 2012;94:351-358.

3 Penkoske PA, Sobel BE, Corr PB: Disparate electrophysiological alterations accompanying dysrhythmia due to coronary occlusion and reperfusion in the cat. Circulation 1978;58:1023-1035. 
Wu et al.: Glycyrrhetinic acid Inhibits Both L-Type Calcium Current (Ica-L) and Transient Outward Potassium Current (Ito) During the Reperfusion Period in Rat Hearts

4 Wu Y, Temple J, Zhang R, Dzhura I, Zhang W, Trimble R, Roden DM, Passier R, Olson EN, Colbran RJ, Anderson ME: Calmodulin kinase II and arrhythmias in a mouse model of cardiac hypertrophy. Circulation 2002;106:1288-1293.

5 Clancy CE, Kass RS: Defective cardiac ion channels: from mutations to clinical syndromes. J Clin Invest 2002;110:1075-1077.

6 Courtemanche M, Ramirez RJ, Nattel S: Ionic targets for drug therapy and atrial fibrillation-induced electrical remodeling: insights from a mathematical model. Cardiovasc Res 1999;42:477-489.

7 Guo D, Liu Q Liu T, Elliott G, Gingras M, Kowey PR, Yan GX: Electrophysiological properties of HBI-3000: a new antiarrhythmic agent with multiple-channel blocking properties in human ventricular myocytes. J Cardiovasc Pharmacol 2011;57:79-85.

8 Yang ZF, Li CZ, Wang W, Chen YM, Zhang Y, Liu YM, Wang HW: Electrophysiological mechanisms of sophocarpine as a potential antiarrhythmic agent. Acta Pharmacol Sin 2011;32:311-320.

9 Edwards CR, Walker BR, Benediktsson R, Seckl JR: Congenital and acquired syndromes of apparent mineralocorticoid excess. J Steroid Biochem Mol Biol 1993;45:1-5.

10 Fiore C, Eisenhut M, Ragazzi E, Zanchin G, Armanini D: A history of the therapeutic use of liquorice in Europe. J Ethnopharmacol 2005;99:317-324.

11 Gumpricht E, Dahl R, Devereaux MW, Sokol RJ: Licorice compounds glycyrrhizin and 18betaglycyrrhetinic acid are potent modulators of bile acid-induced cytotoxicity in rat hepatocytes. J Biol Chem 2005;280:10556-10563.

12 Kao TC, Shyu MH, Yen GC: Glycyrrhizic acid and 18beta-glycyrrhetinic acid inhibit inflammation via PI3K/ Akt/GSK3beta signaling and glucocorticoid receptor activation. J Agric Food Chem 2010;58:8623-8629.

13 Yamaguchi H, Noshita T, Yu T, Kidachi Y, Kamiie K, Umetsu H, Ryoyama K: Novel effects of glycyrrhetinic acid on the central nervous system tumorigenic progenitor cells: induction of actin disruption and tumor cell-selective toxicity. Eur J Med Chem 2010;45:2943-2948.

14 Huang RY, Chu YL, Huang QC, Chen XM, Jiang ZB, Zhang X, Zeng X: 18beta-Glycyrrhetinic acid suppresses cell proliferation through inhibiting thromboxane synthase in non-small cell lung cancer. PLoS One 2014;9:e93690.

15 Guan BC, Si JQ, Jiang ZG: Blockade of gap junction coupling by glycyrrhetinic acids in guinea pig cochlear artery: a whole-cell voltage- and current-clamp study. Br J Pharmacol 2007;151:1049-1060.

16 Howarth FC, Qureshi MA: Effects of carbenoxolone on heart rhythm, contractility and intracellular calcium in streptozotocin-induced diabetic rat. Mol Cell Biochem 2006;289:21-29.

17 Parisella ML, Angelone T, Gattuso A, Cerra MC, Pellegrino D: Glycyrrhizin and glycyrrhetinic acid directly modulate rat cardiac performance. J Nutr Biochem 2012;23:69-75.

18 Rodriguez-Sinovas A, García-Dorado D, Ruiz-Meana M, Soler-Soler J: Enhanced effect of gap junction uncouplers on macroscopic electrical properties of reperfused myocardium. J Physiol 2004;559:245-257.

19 Li X, Wu Y, Guo Z, Liu L: Effect of sodium 18 beta-glycyrrhetate on experimental arrhythmia. Zhongguo Zhong Yao Za Zhi 1992;17:176-178.

20 Du Y, Zhang S, Wu H, Zou A, Lei M, Cheng L, Liao Y: Glycyrretinic acid blocks cardiac sodium channels expressed in Xenopus oocytes. J Ethnopharmacol 2009;125:318-323.

21 Du YM, Xia CK, Zhao N, Dong Q, Lei M, Xia JH: 18beta-Glycyrrhetinic acid preferentially blocks late Na current generated by DeltaKPQ Nav1.5 channels. Acta Pharmacol Sin 2012;33:752-760.

22 Wu D, Jiang L, Wu H, Wang S, Zheng S, Yang J, Liu Y, Ren J, Chen X: Inhibitory effects of glycyrrhetinic Acid on the delayed rectifier potassium current in Guinea pig ventricular myocytes and HERG channel. Evid Based Complement Alternat Med 2013;2013:481830.

23 Lin D, Shanks D, Prakash 0, Takemoto DJ: Protein kinase C gamma mutations in the C1B domain cause caspase-3-linked apoptosis in lens epithelial cells through gap junctions. Exp Eye Res 2007;85:113-122.

24 Elrod JW, Greer JJ, Bryan NS, Langston W, Szot JF, Gebregzlabher H, Janssens S, Feelisch M, Lefer DJ: Cardiomyocyte-specific overexpression of NO synthase-3 protects against myocardial ischemia-reperfusion injury. Arterioscler Thromb Vasc Biol 2006;26:1517-1523.

25 Walker MJ, Curtis MJ, Hearse DJ, Campbell RW, Janse MJ, Yellon DM, Cobbe SM, Coker SJ, Harness JB, Harron DW: The Lambeth Conventions: guidelines for the study of arrhythmias in ischaemia infarction, and reperfusion. Cardiovasc Res 1988;22:447-455.

26 Aparci M, Isilak Z, Uz O, Kardesoglu E, Yiginer O, Sildiroglu O, Yalcin M, Ozmen N, Cingozbay BY, Cebeci BS: Increased P wave dispersion in patients with liver steatosis. Med Glas (Zenica) 2010;7:143-147. 
Wu et al.: Glycyrrhetinic acid Inhibits Both L-Type Calcium Current (Ica-L) and Transient Outward Potassium Current (Ito) During the Reperfusion Period in Rat Hearts

27 Anversa P, Cheng W, Liu Y, Leri A, Redaelli G, Kajstura J: Apoptosis and myocardial infarction. Basic Res Cardiol 1998;93:S8-12.

28 Balaban RS, Nemoto S, Finkel T: Mitochondria, oxidants, and aging. Cell 2005;120:483-495.

29 Jennings RB, Sommers HM, Smyth GA, Flack HA, Linn H: Myocardial necrosis induced by temporary occlusion of a coronary artery in the dog. Arch Pathol 1960;70:68-78.

30 Vanden Hoek TL, Shao Z, Li C, Zak R, Schumacker PT, Becker LB: Reperfusion injury on cardiac myocytes after simulated ischemia. Am J Physiol 1996;270:H1334-341.

31 Yellon DM, Hausenloy DJ: Myocardial reperfusion injury. N Engl J Med 2007;357:1121-1135.

32 Monassier JP: Reperfusion injury in acute myocardial infarction. From bench to cath lab. Part I: Basic considerations. Arch Cardiovasc Dis 2008;101:491-500.

33 Braunwald E, Kloner RA: The stunned myocardium: prolonged, postischemic ventricular dysfunction. Circulation 1982;66:1146-1149.

34 Bolli R, Marban E: Molecular and cellular mechanisms of myocardial stunning. Physiol Rev 1999;79:609634.

35 Manning AS, Hearse DJ: Reperfusion-induced arrhythmias: mechanisms and prevention. J. Mol. Cell Cardiol 1984;16:497-518.

36 Manning AS, Coltart DJ, Hearse DJ: Ischemia and reperfusion-induced arrhythmias in the rat. Effects of xanthine oxidase inhibition with allopurinol. Circ Res 1984;55:545-548.

37 Krug A, Du Mesnil d R, Korb G: Blood supply of the myocardium after temporary coronary occlusion. Circ Res 1966;19:57-62.

38 Jensen PK: Antimycin-insensitive oxidation of succinate and reduced nicotinamide-adenine dinucleotide in electron-transport particles. I. pH dependency and hydrogen peroxide formation. Biochim Biophys Acta 1966;122:157-166.

39 Andreyev AY, Kushnareva YE, Starkov AA: Mitochondrial metabolism of reactive oxygen species. Biochemistry (Mosc.) 2005;70:200-214.

40 Singh VP, Rubinstein J, Arvanitis DA, Ren X, Gao X, Haghighi K, Gilbert M, Iyer VR, Kim do H, Cho C, Jones K, Lorenz JN, Armstrong CF, Wang HS, Gyorke S, Kranias EG: Abnormal calcium cycling and cardiac arrhythmias associated with the human Ser96Ala genetic variant of histidine-rich calcium-binding protein. J Am Heart Assoc 2013;2:e000460.

41 Haigney MC, Lakatta EG, Stern MD, Silverman HS: Sodium channel blockade reduces hypoxic sodium loading and sodium-dependent calcium loading. Circulation 1994;90:391-399.

42 Pinet C, Le Grand B, John GW, Coulombe A: Thrombin facilitation of voltage-gated sodium channel activation in human cardiomyocytes: implications for ischemic sodium loading. Circulation 2002;6:20982103.

43 Álvarez P, Tapia L, Mardones LA, Pedemonte JC, Farías JG, Castillo RL. Cellular mechanisms against ischemia reperfusion injury induced by the use of anesthetic pharmacological agents. Chem Biol Interact 2014;218:89-98.

44 Gonca E, Bozdogan O: Both mitochondrial KATP channel opening and sarcolemmal KATP channel blockage confer protection against ischemia/reperfusion-induced arrhythmia in anesthetized male rats. J Cardiovasc Pharmacol Ther 2010;15:403-411.

45 Yu W, Wang JJ, Gan WY, Lin GS, Huang CX: Effects of verapamil preconditioning on cardiac function in vitro and intracellular free Ca2+ and L-type calcium current in rat cardiomyocytes post ischemia-reperfusion injury. Zhonghua Xin Xue Guan Bing Za Zhi 2010;38:225-229.

46 Chen WP, Hung LM, Hsueh CH, Lai LP, Su MJ: Piceatannol, a derivative of resveratrol, moderately slows $\mathrm{I}(\mathrm{Na})$ inactivation and exerts antiarrhythmic action in ischaemia-reperfused rat hearts. Br J Pharmacol 2009;157:381-391.

47 Burashnikov A, Antzelevitch C: Novel pharmacological targets for the rhythm control management of atrial fibrillation. Pharmacol Ther 2011;132:300-313. 